\title{
Budd Chiari syndrome in a patient with Celiac disease: A rare entity
}

\author{
Hina Ismail'1, Zain Majid², Zahid Shah³ ${ }^{3}$ Ghazi Abrar', Raja Taha Yaseen Khan', \\ Farina Hanif ${ }^{6}$, Nasir Hasan Luck ${ }^{7}$ \\ 1,3,4,5 Post Graduate Trainee, ${ }^{2}$ Consultant, ${ }^{5}$ Senior Registrar, ${ }^{6}$ Associate Professor, ${ }^{7}$ Professor, Department of Hepato- \\ Gastroenterology, Sindh Institute of Urology and Transplantation, Sindh Institute of Urology and Transplantation, \\ Karachi, Pakistan
}

\section{A B S T R A C T}

Celiac disease is an immune mediated enteropathy that causes malabsorption. It is associated with a number of autoimmune diseases, however is rarely associated with Budd chiari syndrome. We present a case of a young girl who was a diagnosed case of celiac disease and had presented with abdominal distension along with pedal edema. Her initial workup was all negative while ultrasound abdomen along with CT scan abdomen had given the impression of Budd chiari syndrome. She was managed with gluten free diet, diuretics along with anticoagulants.

Key words: Celiac disease; Budd chiari syndrome; Malabsorption; Thrombolytics

\section{Access this article online}

Website:

http://nepjol.info/index.php/AJMS DOI: 10.3126/ajms.v12i9.37430

E-ISSN: 2091-0576 P-ISSN: 2467-9100

Copyright (c) 2021 Asian Journal of Medical Sciences

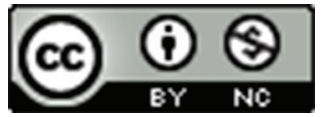

This work is licensed under a Creative Commons Attribution-NonCommercial 4.0 International License.

\section{INTRODUCTION}

Celiac disease is one of the commonest cause of chronic malabsorption. It is an immune mediated enteropathy that is triggered by the consumption of dietary gluten in genetically prone individuals that leads to symptoms of malabsorption such as diarrhea, steatorrhea, weight loss and nutritional deficiencies. ${ }^{1}$ The incidence of $\mathrm{CD}$ is considerably increased in patients having first degree family member affected with CD. The diagnosis is made when there is concordance between serological results and biopsy findings.

$\mathrm{CD}$ has an association with autoimmune liver diseases (primary biliary cirrhosis and autoimmune hepatitis) and an isolated hypertransaminasemia may occasional be present. ${ }^{2}$
Budd- Chiari syndrome, which is characterized by the thrombosis of the hepatic veins, is a rare entity having an incidence rate of one case per 100000 individuals. ${ }^{3}$

Celiac disease is rarely associated with Budd Chiari Syndrome and we hereby through our case report would like to highlight this association.

\section{Case presentation}

A 15 years old female girl, diagnosed case of celiac disease (based upon TTG serology and duodenal biopsy (Image 1) and compliant on gluten-free diet for the past 6 years, presented to our outpatients' department with abdominal pain along with distension and pedal edema for past one month. Her physical examination showed pallor, mild icterus and bilateral pedal edema. Further examination 


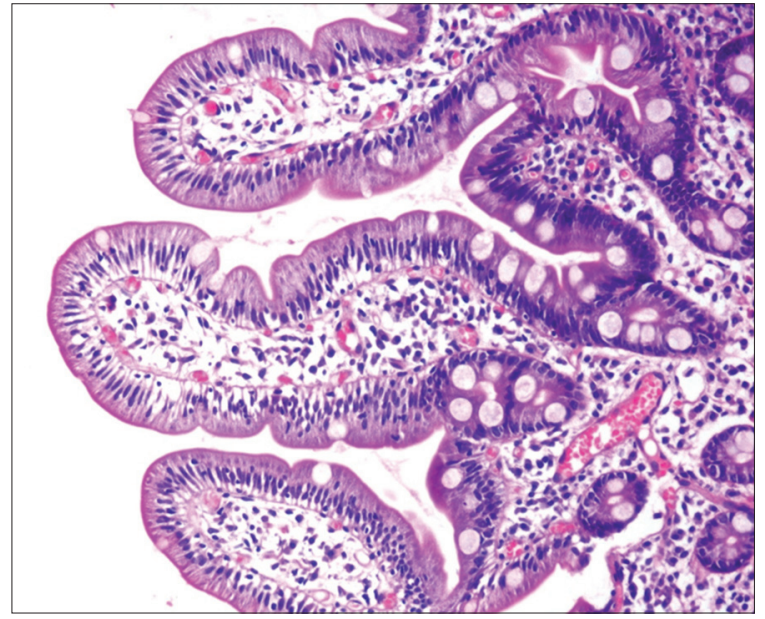

Image 1: Showing blunting and flattening of villi-findings consistent with Sprue Marsh class $3 \mathrm{~A}$

showed distended abdomen along with an enlarged and tender liver having a liver span of $16 \mathrm{~cm}$ and a palpable spleen $4 \mathrm{~cm}$ below the left costal margins.

Her complete blood count $(\mathrm{CBC})$ revealed a hemoglobin level of $6.8 \mathrm{~g} / \mathrm{dl}$, mean corpuscular volume of $63.9 \mathrm{fL}$, total leukocyte count of $9.2 \times 109 / \mathrm{L}$, and a platelet count of $156 \times 10^{\circ} / \mathrm{L}$. Peripheral blood film showed microcytic hypochromic red blood cells. Liver function tests disclosed a total bilirubin of $1.78 \mathrm{mg} / \mathrm{dl}$, alanine aminotransferase 65U/L (normal 0-37 U/L), aspartate aminotransferase $37(0-40 \mathrm{U} / \mathrm{L})$ and albumin $1.52 \mathrm{~g} / \mathrm{dL}$. The international normalized ratio was 1.75 . Viral markers were negative (HBsAg and anti HCV). Her Serum iron was low $31 \mu \mathrm{g} / \mathrm{dL}$ while serum Ferritin levels were within normal limits $94 \mu \mathrm{g} / \mathrm{dL}$ (normal $40-155 \mathrm{mg} / \mathrm{dl}$ and 11-307ug/dL). Vitamin b12 levels were normal $445 \mathrm{pg} / \mathrm{mL}$, normal: $211-900 \mathrm{pg} / \mathrm{mL}$ ).

Based upon her initial presentation, Ultrasound abdomen was done which depicted an enlarged liver having irregular margins and marked splenomegaly $(16 \mathrm{~cm})$ along with gross ascities. Ascitic fluid analysis was done which was consistent with the findings of portal hypertension: high serum-ascites albumin gradient or gap (SAAG), low protein ascites. For further workup Serum ceruloplasmin levels were sent and were normal, while the slit-lamp examination was also negative for Kayser-Fleischer ring. Autoimmune serology (anti-nuclear antibodies and anti-smooth muscle antibodies) was also negative. Thyroid profile, renal function tests were within normal limits.

Later on, a Doppler ultrasound of the liver was planned which revealed thin caliber hepatic vein, having no flow on CDI along with hypertrophy of the caudate lobe. In order to confirm our findings, we proceeded with a Contrast -enhanced computed tomography (CT) of the abdomen (Image 2), which revealed the liver to have irregular margins and appeared mottled and edematous. Caudate lobe was enlarged in size measuring $5.6 \times 5.2 \mathrm{~cm}$. Intrahepatic part of IVC was significantly thinned and there was non visualization of the hepatic veins. Multiple collaterals formation was noted at splenic hilum. A Focal filling defect of $1.1 \mathrm{x} 0.9 \mathrm{~cm}$ with surrounding calcification was noted in one of the collaterals channels, representing partial thrombus. Findings were consistent with Budd chiari syndrome.

Her Esophagogastroduodenoscopy had revealed one column of grade II varices (without red sign).

Her Thrombophilia profile was unrevealing (lupus anticoagulant, protein $\mathrm{C}$ and protein $\mathrm{S}$, antithrombotic III and factor V Leiden)

The patient was managed conservatively with anticoagulants, diuretics (spironolactone with furosemide) along with beta blockers. She was started on low salt and high protein diet along with GFD, iron and B12 supplements. On follow up after one month, patient had improvement in symptoms in terms of ascites and increase in hemoglobin.

\section{DISCUSSION}

This case outlines the occurrence of BCS in a diagnosed case of CD. Since she was complaint to GFD, in spite of that she developed features of BCS in the absence of any hypercoagulable state. Association of BCS with $\mathrm{CD}$ was first defined in $1990 .{ }^{4}$ Review of the literature showed that most of the cases reported were from North African Arab countries and Southern Europe..$^{5-8}$ Literature review showed three cases from another region of the world (India and Argentina)..$^{9-11}$

Our case is the first to be reported from Pakistan. According to the recent survey $61 \%$ of the patient of $\mathrm{CD}$ with BCS has no underlying thrombotic etiology as seen in our case. ${ }^{12}$ previously reported cases have shown that most patients have been presented in their third and fourth decade. BCS is more commonly seen in females, with some propensity to present at an advanced age than male patients. The BCS can present in acute, subacute, fulminant and chronic form in patients with $\mathrm{CD}$ with later being the commonest presentation similar to the patient in our case.

The most common cause of BCS is primary myeloproliferative disorders. Although nearly half of the patients have more than one causative factor accountable for the underlying hypercoagulable state. The number of theories has been suggested the association of $\mathrm{CD}$ 


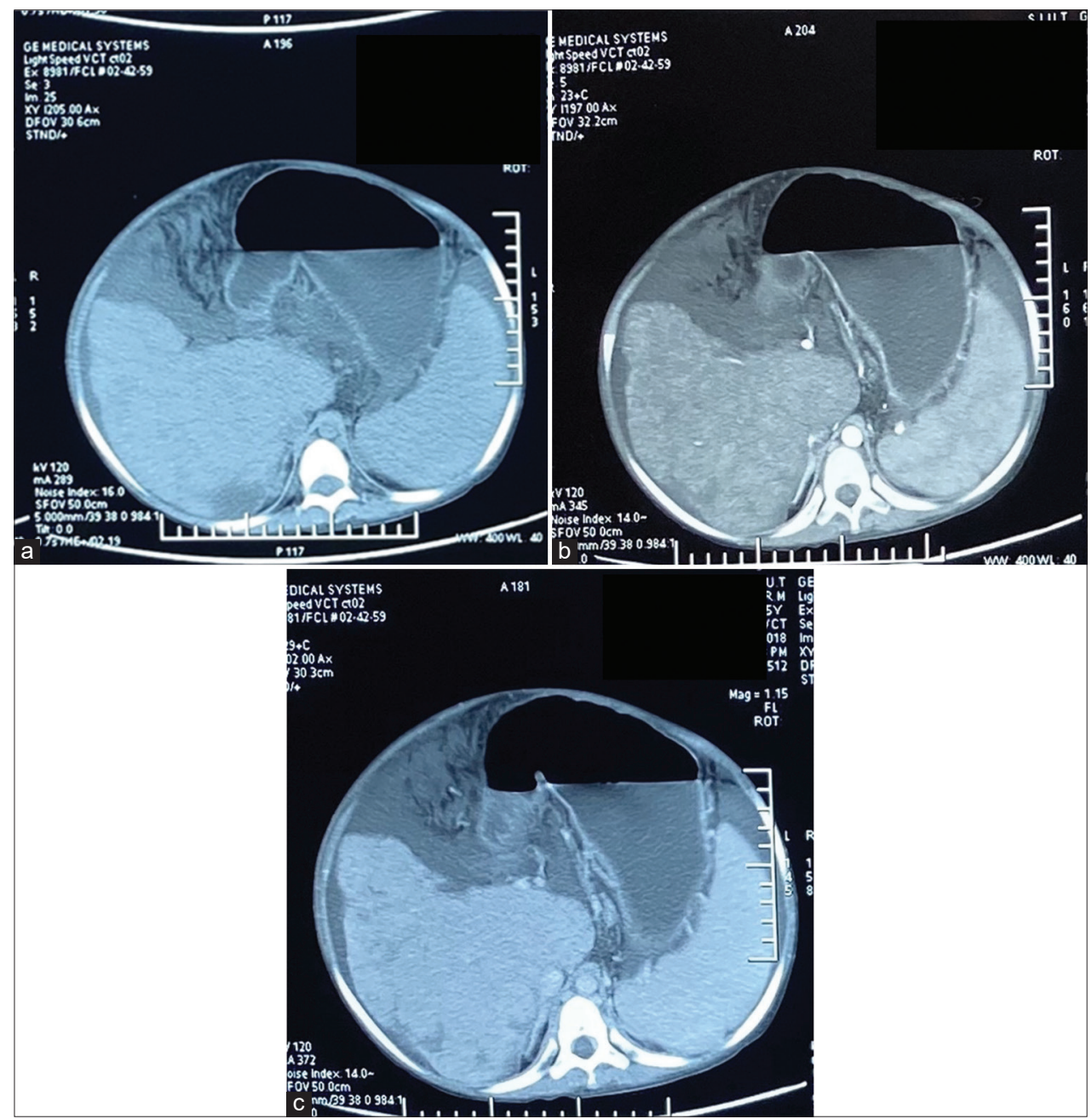

Image 2: CT scan abdomen (plain (a), arterial (b) and portovenous phase(c)) showing the liver having a mottled and edematous with an enlarged caudate lobe and non-visualization of the hepatic veins along with moderate ascites. Findings consistent with the diagnosis of Budd chiari syndrome

with BCS. It was proposed that the possible etiological factors are ethnic, genetic or environmental because all cases were reported from the same geographical region. Moreover, in the patients of CD associated with BCS, no specific thrombotic cause was found as in our case. It is demonstrated by several theories. Hyposplenism in CD can be responsible for the hypercoagulable state. Malabsorption of vitamin $\mathrm{K}$ leading to protein $\mathrm{C}, \mathrm{S}$ and ant thrombin III deficiency, autoimmune vasculitis ${ }^{13}$ magnesium deficiency ${ }^{14}$ hyperhomocysteinemia secondary to folate deficiency or MTHFR (methylene tetrahydrofolate reductase) gene mutation $^{15}$ are other mechanisms leading to thrombosis in BCS.

To conclude, we reported a rare association of BCS in CD from Pakistan and enlightened some factors possibly responsible for the vascular thrombosis in CD. More studies are required to know the underlying mechanism. We suggest every clinician should rule out BCS while evaluating a patient of $\mathrm{CD}$ of undetermined liver disease.

\section{REFERENCES}

1. Green PH. The many faces of celiac disease: clinical presentation of celiac disease in the adult population. Gastroenterology. 2005;128(4): S74-S78.

https://doi.org/10.1053/j.gastro.2005.02.016

2. Ludvigsson JF, Elfström $P$, BroomÉ U, Ekbom A and Montgomery SM. Celiac disease and risk of liver disease: a general population-based study. Clinical Gastroenterology and Hepatology. 2007;5(1):63-69.

https://doi.org/10.1016/j.cgh.2006.09.034

3. Valla DC. The diagnosis and management of the Budd $\square$ Chiari syndrome: consensus and controversies. Hepatology. 2003;38(4):793-803.

https://doi.org/10.1053/jhep.2003.50415

4. Boudhina T, Ghram N, Ben Becher S, Ayach R, Ben Ghachem K, Yedes A, et al. Budd-Chiari syndrome and total villous atrophy in children: apropos of 3 case reports. Tunis Med. 1990; 68(1): 59-62.

5. Manzano ML, Garfia C, Manzanares J, Urruzuno P, Yela C, Castellano G, et al. Celiac disease and Bud-Chiari syndrome: an uncommon association. Gastroenterol Hepatol. 2002;25(3): $159-161$. 
https://doi.org/10.1016/S0210-5705(02)79011-0

6. Danalioğlu A, Poturoğlu $S$, Güngör Güllüoğlu $M$, Demir $K$, Beşişik $F$ and Cakaloğlu $Y$. Budd-Chiari syndrome in a young patient with celiac sprue: a case report. Turk J Gastroenterol.2003;14(4):262-265.

7. Jadallah KA, Sarsak EW, Khazaleh YM and Barakat RM. BuddChiari syndrome associated with coeliac disease: case report and literature review. Gastroenterology report. 2018;6(4):308-312. https://doi.org/10.1093/gastro/gow030

8. Afredj N, Metatla S, Faraoun SA, Nani A, Guessab N, Benhalima M, et al. Association of Budd-Chiari syndrome and celiac disease. Gastroentérologie clinique et biologique. 2010;34(11):621-624. https://doi.org/10.1016/j.gcb.2010.07.007

9. Kochhar R, Masoodi I, Dutta U, Singhal M, Miglani A, Singh P, et al. Celiac disease and Budd Chiari syndrome: report of a case with review of literature. European journal of gastroenterology and hepatology. 2009;21(9):1092-1094.

https://doi.org/10.1016/j.gcb.2010.07.007

10. Aguirrebarrena G, Pulcinelli S, Giovannoni AG and Gidekel L. Celiac disease and Budd-Chiari syndrome: infrequent association. Revista espanola de enfermedades digestivas: organo oficial de la Sociedad Espanola de Patologia Digestiva.
2001;93(9):611.

11. Meena DS, Sonwal VS, Bohra GK, Balesa J and Rohila AK. Celiac disease with Budd-Chiari syndrome: A rare association. SAGE open medical case reports. 2019; 7:2050313X19842697. https://doi.org/10.1177/2050313X19842697

12. Jadallah KA, Sarsak EW, Khazaleh YM and Barakat RM. BuddChiari syndrome associated with coeliac disease: case report and literature review. Gastroenterology report. 2018;6(4):308-312. https://doi.org/10.1093/gastro/gow030

13. Vives MJ, Esteve M, Mariné M, Fernández-Bañares F, Alsina M, Salas A, et al. Prevalence and clinical relevance of enteropathy associated with systemic autoimmune diseases. Digestive and Liver Disease. 2012;44(8):636-642. https://doi.org/10.1016/j.dld.2012.02.013

14. Durlach J. Celiac disease, magnesium deficiency and venous thrombosis. Presse medicale (Paris, France: 1983). 2001.;30(18):904.

15. Wilcox GM and Mattia AR. Celiac sprue, hyperhomocysteinemia, and MTHFR gene variants. Journal of clinical gastroenterology. 2006;40(7):596-601.

https://doi.org/10.1097/00004836-200608000-00007

Authors Contribution:

HI, ZS, GA - Patient management; ZM, RTYK - Manuscript drafting; FH, NHL- Final correction.

Work attributed to:

Department of Hepato-gastroenterology, SIUT, Karachi, Pakistan.

Orcid ID:

Dr. Zain Majid - (1) https://orcid.org/0000-0002-6961-3011

Source of Support: Nil, Conflict of Interest: None declared. 